\title{
Investigating the Relationship between Perceived Leader's Dark Triad Traits and Job Performance \\ (An Empirical Study on Egyptian National newspapers' \\ Journalists)
}

\section{Prof. Abdel-Hakeem Ahmed Nagm}

Professor of Business Management,

Faculty of Commerce,

Mansoura University

\section{Eman Elsayed Elfar}

Assistant Lecturer at Business Administration Department

Faculty of Business Administration - Delta University for Science\&
Dr. Ahmed Mohamed Elsetouhi

Lecturer of Business Management, Faculty of Commerce, Mansoura University

Technology

\begin{abstract}
The research aims to examine the relationship between perceived leader's dark triad traits and journalists' job performance (Task performance, contextual performance, and creative performance). Data were collected from 391 journalists at Egyptian national newspapers. The research employed a quantitative research method and regression analysis technique to test the research hypotheses through Warp PLS version 6. The research findings highlighted that perceived leader's dark triad traits had a significant effect on journalists' job performance (task performance, contextual performance, and creative performance). The $\mathrm{R}^{2}$ values of these effects are $(0.05,0.021$, and 0.024 ; respectively).
\end{abstract}

Keywords: Dark triad traits, Job performance.

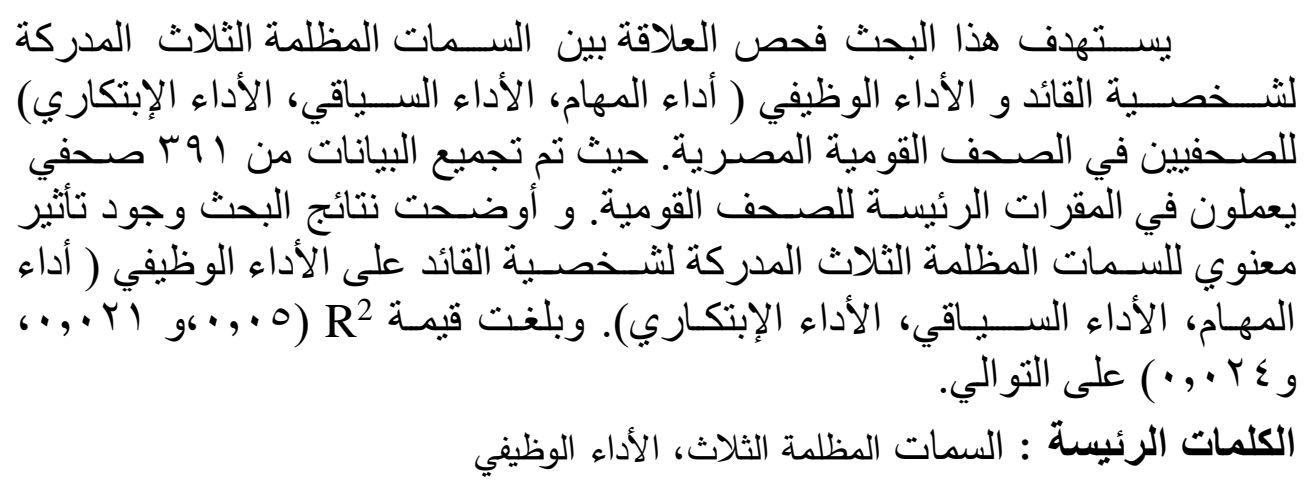




\section{Introduction}

Although, the higher economical, organizational, and societal costs of dark triad traits, most researches in leadership literature have focused on positive personality traits and its organizational outcomes (Murray, 2016). Dark leaders show many counterproductive work behaviors. They usually seek for managerial positions to get the organizational power, and depend on explorative behaviors. Besides that, they aim to achieve their goals and interests regardless the interest of their organization (Rauthmann, 2012). Therefore, there is an increasing need for studying dark personalities to understand its dimensions, determining their organizational effects, and how to deal with them (Spain et al., 2013).

Tejedor et al. (2015) stated that the leaders' personality traits have strong effect on the employees performance since leader's positive traits lead to motivate individual to achieve higher performance level and increase his/her effectiveness. Job performance is defined as scalable behaviors, actions, and outcomes in which employee engages in and contributes to organizational goals

This research contributes to both leadership and human resources field literature by (1) illustrating a theoretical clarification for why dark leaders may have a positive effect on their subordinates' job performance. (2) Discussing the effects of perceived leader's dark triad traits on both of task performance, contextual performance, and creative performance. (3) Providing new insights through explaining how journalists could maintain and reinforce their positive behaviors under the supervision of dark leaders.

\section{Literature review}

\subsection{Dark triad traits}

Dark leadership is described as a destructive leadership in which the leader puts his/her own interest over the organization's interest and misuses his /her organizational power (Murray, 2016). Smith and Lilienfeld (2013) have defined dark triad traits as a set of three dimensions that describe maladaptive personality traits. Paulhus and William (2002) also explained 
dark triad as personality traits that describe individuals who have a tendency to be malevolent, selfish, and callous in their interpersonal relations.

In general, dark triad traits are the collection of three personality traits: narcissism, Machiavellianism, and psychopathy (Knight, 2016; Murray, 2016). These traits share common characteristics like callousness, low empathy, participation in criminal activities, and opportunistic behaviors (Knight, 2016). Besides, Dark triad traits have similar malevolent traits and dysfunctional, destructive, and problematic behaviors (Klann, 2017). The common feature between these traits is that they are undesirable characteristics but still within the range of normal personalities (Murray, 2016).

\subsubsection{Machiavellianism}

Christie and Geis (1970) were the initial researchers who studied Machiavellianism and explained the difference between high Machiavellians and low Machiavellians according to the level of emotions they invest in the interpersonal relations (Macneil, 2008). Machiavellians follow Niccole Machiavelli's principle "ends justify the means" (Benton, 2016). They have three basic beliefs: depending on manipulative tactics in interpersonal relation, expediency above principles, and cynical view toward others (Deshong, 2013).

Furthermore, three basic philosophies boost Machiavellians. Frist, individuals are gullible, fallible, and weak. Second, the rational individual should exploit these characteristics to achieve personal gain. Third, individual should protect his/her own interest from foolishness of other (Butler, 2015).

On one hand, Machiavellians exert great effort in order to hide their negative personality and to maintain positive reputation instead. Although Machiavellians are denoted by cynicism, egocentricity, showing distrust, and interpersonal manipulation, they are best known for being charming, charismatic, double-faced and seductive individuals (Macneil, 2008; Butler, 2015). They are characterized by the lack of empathy and conscientiousness, pragmatic, cynical, unmoral beliefs, misanthropic, self-beneficial, exploitation, manipulation, deception, being task oriented, and duplicity 
(Deshong, 2013). Machiavellians are also able to change their behaviors in different situation

On the other hand, high Machiavellians show flexibility in doing both their unstructured and structured tasks. They tend to be more persuasive, likeable, and intelligent (Macneil, 2008). High Machiavellians sometimes appear to be charismatic and likable leaders because of their ability to be sympathetic. Moreover, they often achieve a notable success in concealing their cruel intensions. They seek to have positive reputation through build alliances and do not act impulsively (Butler, 2015).

\subsubsection{Narcissism}

Narcissism is not only the core of dark leadership but it is also the core of leadership itself because of the great correlation between narcissism and leadership (Butler, 2015; Murray, 2016). According to Murray (2016), narcissism includes personality traits such as: overstating individual's positive quantity, and trying to manipulate others to achieve their personal goals and satisfy their egos. The first definition of narcissism was published in 1980 and explained the main characteristic of narcissism as 1- fantasies about personal power, success, etc., 2- refuse criticism from others, 3- grandiosity, 4entitlement, 5- exhibitionism (attract others' attention), 6- interpersonal utilization, and finally 7- lack the empathy (Butler, 2015). Moreover, the definition of narcissism has changed according to DSM-5. The DSM-5 explained that the narcissistic individual has at least five of the following characteristics: a gorgonize sense of his/her importance, fantasies toward his/her unlimited power, beauty and success, believing in his/her specialty and uniqueness, feeling of entitlement, exploitation, lacking empathy, the believing that he/she is envois, and arrogance (Grondel, 2016).

Furthermore, the narcissism has four basic beliefs. Frist, narcissists manipulate others to achieve their benefits. Second, narcissists are talent leaders. Third, narcissists feel their superiority over other. Fourth, they believe in the fact that they deserve other's respect and admiration. In addition, Macneil (2008) proposed that the narcissists often believe that the life is a mean by which they can achieve their desired status, success and admiration. Thus, they depend on social environment so as to maintain their 
self-perception and get positive feedback. Finally, Narcissists focus more on the extrinsic goals than the intrinsic goals.

Benton (2016) also stated the basic four dimensions of narcissistic leadership are amorality, self-serving, exploitation of followers, and abuse of power. Even though, narcissistic leaders usually seem to be charismatic leaders and often they try to attract others' admiration and to get their attention. Narcissistic leadership is more acceptable in western culture as it focuses more on the achievement and boldness (Murray, 2016).

Lastly, Knights (2014) highlighted the fact that narcissistic leaders can brings in benefit to their organization in two ways. First, utilizing their creative visions. Narcissists can predict the future and snatch the opportunities that would help them to have competitive positions. Second, Charisma is the secret behind achieving success in the different organizations. They use their emotional intelligence to persuade their followers. Like charismatic leaders, narcissistic leaders influence their subordinates to achieve superior organizational performance (Knights, 2014).

\subsubsection{Psychopathy}

Psychopathic individuals are the most dangerous, socially undesirable, and toxic traits between dark triad traits (Butler, 2015: Murray, 2016). The description of psychopathy characteristics was presented by Cleckley in 1988. Cleckley (1988) initially described psychopathy concept by 16 personality traits. These traits are: superficial charming, unreliability, egocentric, lack of remorse, low level of anxiety, deceitful, do not learn from past experience, don't accept balm or punishment, have not the sense of shame, lack affect and emotions, non-nervous, untruthful, insincere, performing antisocial behavior, failure in strategic planning, and cannot take proper response in interpersonal relationship (Macneil, 2008; Baker, 2013; Carre, 2016). Cleckley (1988) also stated that these characteristics vary in their degrees, and interfere with other normal personalities.

Later, Hare (1993-1996) described psychopaths as individuals who have remorseless, callous view toward others' feeling and rights, and antisocial lifestyle. Murray (2016) stated that the most deferential characteristics of psychopathy is the tendency for aggression. Psychopathy is 
related to high level of criminal activities, risk- taking behaviors, causing institutional problems, impulsiveness, and low response toward treatment (Macneil, 2008; Knight, 2016). They also associated with alcohol and drugs consumption, violence, and sometimes fall in trouble with justice system (Carre, 2016; Murray, 2016).

The core features of psychopaths are thrill-seeking, high impulsivity, lack empathy and guilt, believing that legal penalties are not applicable on them, low impulse control, and poor judgment. They are also characterized to be egocentric, irrational thinking, duplicity, cold-hearted, arrogant, low conscientiousness, manipulative, grandiose, selfish, and forceful (Spain et al., 2013; Butler, 2015; Murray, 2016). Psychopaths are also recognized for emotional stability, callousness, erratic behaviors, lacking emotional insights, and recklessness (Murray, 2016). In additions, Psychopaths belief highly in their superiority, seek self-promotion, and being antagonistic (Spain et al., 2013).

Despite all of that, psychopaths are highly skilled in impression management, charismatic, glib, and exploit other people to obtain their support (Deshong, 2013). Psychopathic leader looks as smart one by bullying, cunning, and manipulator. Despite their destructive behaviors, psychopaths achieve success in their work environment through depending on their tendency to use both ethical and unethical tactics to maintain their success (Murray, 2016).

\subsection{Job performance}

Johnson (2009) defined individual overall performance as the value he/she add to the organization's goals over specific period. Job performance is also defined as scalable behaviors, actions, and outcomes in which employees engage in and contribute to organizational goals. Borman and Motwoidlo (1997) presented model of job performance that proposed that job performance consists of two basic dimensions: task performance and contextual performance. Additionally, in dynamic work environment, creativity plays a vital role in achieving organizational competitiveness. Therefore, having high levels of creative performance is an essential element for organizational innovation and maintaining competitive advantage 
(Gilson, 2000). Consequently, the researchers will assume creative performance as one of job performance dimensions because of its importance.

\subsubsection{Task Performance}

Borman and Motwoidlo (1997) asserted that task performance is a basic dimension of job performance. Task performance consists of behaviors that enhance the technical aspects of organization's job both indirectly and directly (Brownlee, 1999; Bellia, 2007; Johnson, 2009). Williams and Anderson (1991) also explained task performance as the extent to which the employee perform the formal job's requirements and carry out job duties.

Additionally, task performance is correlated to the technical core of the organization and focuses on carrying out activities that lead to produce and deliver organization's products that in turn enhance the organizational effectiveness (Abod, 2001; Bonness, 2007). Task performance behaviors are usually described in job description and organizations reward them (Brownlee, 1999; Johnson, 2009). In addition, task performance depends on job specific knowledge, and focus on both administrative and technical behaviors that promote the job's technical aspect.

\subsubsection{Contextual Performance}

Contextual performance includes activities that do not focus on the technical aspect of the job but reinforce the psychological and social environment in which employee performs his/her task (Brownlee, 1999; Bellia, 2007; Johnson, 2009). Contextual performance is discretionary behaviors and does not exist in the formal job description so it is considered as extra role behaviors (Brownlee, 1999; Abod, 2001).

Furthermore, contextual performance involves the activities that enhance the organizational and social network. It also boosts the psychological climate in terms of helping others and voluntary performing tasks that are not mentioned in the job description. It also represents the way by which employees engage in the work (Guerra, 2015). Besides, Contextual performance indirectly contributes to organization's technical core through activities like managing human resources, supplying the raw material, 
providing maintenance service, and supporting positive work context (Johnson, 2009).

Contextual performance also helps organizations to reinforce team effectiveness, allows the proper allocation of organizational resource, and handles unanticipated problem. Thus, contextual performance affects both overall performance and organizational effectiveness (Bellia, 2007; Bonness, 2007).

\subsubsection{Creative performance}

Togade (2007) described the creative performance as a learned behavior since the individual is not creative by nature. Creativity is described as the creation of novel and useful ideas related to organizational procedures, practices, and products (Lucas, 2015). Ideas are considered novel when they are unique and different from other existing ideas. Additionally, ideas are considered useful when they add value to the organization.

In addition, Amabile (1983) defined the creativity as the process of creation original quality product that others judge it as creative. Creative product should be characterized by novelty, usefulness, and appropriateness (Madjar, 2002; Arendet, 2006).

On one level, Montag, Maertz, and Baer (2012) posited that creative performance consists of two components. Frist, creative performance behaviors which is defined as a group of interdependent unobservable and observable activities that happen as a result of non-algorithmic task and constitute creative process. Second, creative outcome effectiveness which is described as the extent to which relevant stakeholders judge task's outcomes to be useful and novel (Chatterjee, 2016).

On the other level, the componential model of creativity that was presented by Amabile's in 1996 defined the five stages of creative performance. Firstly, the presentation of a problem or tasks. Secondly, the preparation for generating ideas or solutions for a given task or problem (Jeon, 2008). Thirdly, the actual generation of response for the given problem or task. Fourthly, validation. Finally, the outcomes of creative process (Jeon, 2008). 


\subsection{Dark triad traits and Job Performance:}

Judge et al. (2006) explained that there were negative effects of narcissism on other's rating of contextual performance. Whereas, there was no relation between narcissism and task performance. On the other level, Goncalo et al. (2010) found that narcissism was positively correlated to creativity. However, there was no link between narcissism and creative performance. Furthermore, O'Boyle et al. (2012) meta-analysis study concluded that both Psychopathy and Machiavellianism were related to decreased job performance, while all dark triad traits were positively associated with counterproductive work behaviors. These results indicated that dark triad traits were more related to dark behaviors in workplace. In positions with high authority, narcissism and job performance were significantly and negatively related.

Besides that, the research results of Grijalva and Newman (2015) are consistent with O'Boyle et al. (2012) that confirmed that narcissism was positively predict counterproductive work behaviors. Scherer et al. (2013) agreed with O'Boyle et al. (2012) that there was a significant relation between subclinical psychopathy and counterproductive work behavior.

Zettler and Solga (2013) also found that Machiavellianism has a negative correlation with task performance and organizational citizenship behaviors. Furthermore, Wisse et al. (2015) stated that Machiavellianism has a significant negative effect on employee innovative behavior. While, employee narcissism has a positive effect on employee innovative behavior. The researchers justified these results as Machiavellians focus on their needs without paying attention to other's which weaken their innovative behavior. On the other hand, the existence of the high competition between narcissistic employees foster their creative and innovative behaviors to get supervisor's admiration.

After reviewing the previous studies, the researchers suggested the following hypothesis (see figure 1):

H1: H.1: Perceived leader's dark triad traits (Machiavellianism, narcissism, and psychopathy) have a significant direct effect on job performance (task performance, Contextual performance, and creative performance) 
This hypothesis is divided into three main sub- hypotheses:

H1a: Perceived leader's dark triad traits (Machiavellianism, narcissism, and psychopathy) have a significant direct effect on task performance.

H1b: Perceived leader's dark triad traits (Machiavellianism, narcissism, and psychopathy) have a significant direct effect on contextual performance.

H1c: Perceived leader's dark triad traits (Machiavellianism, narcissism, and psychopathy) have a significant direct effect on creative performance.

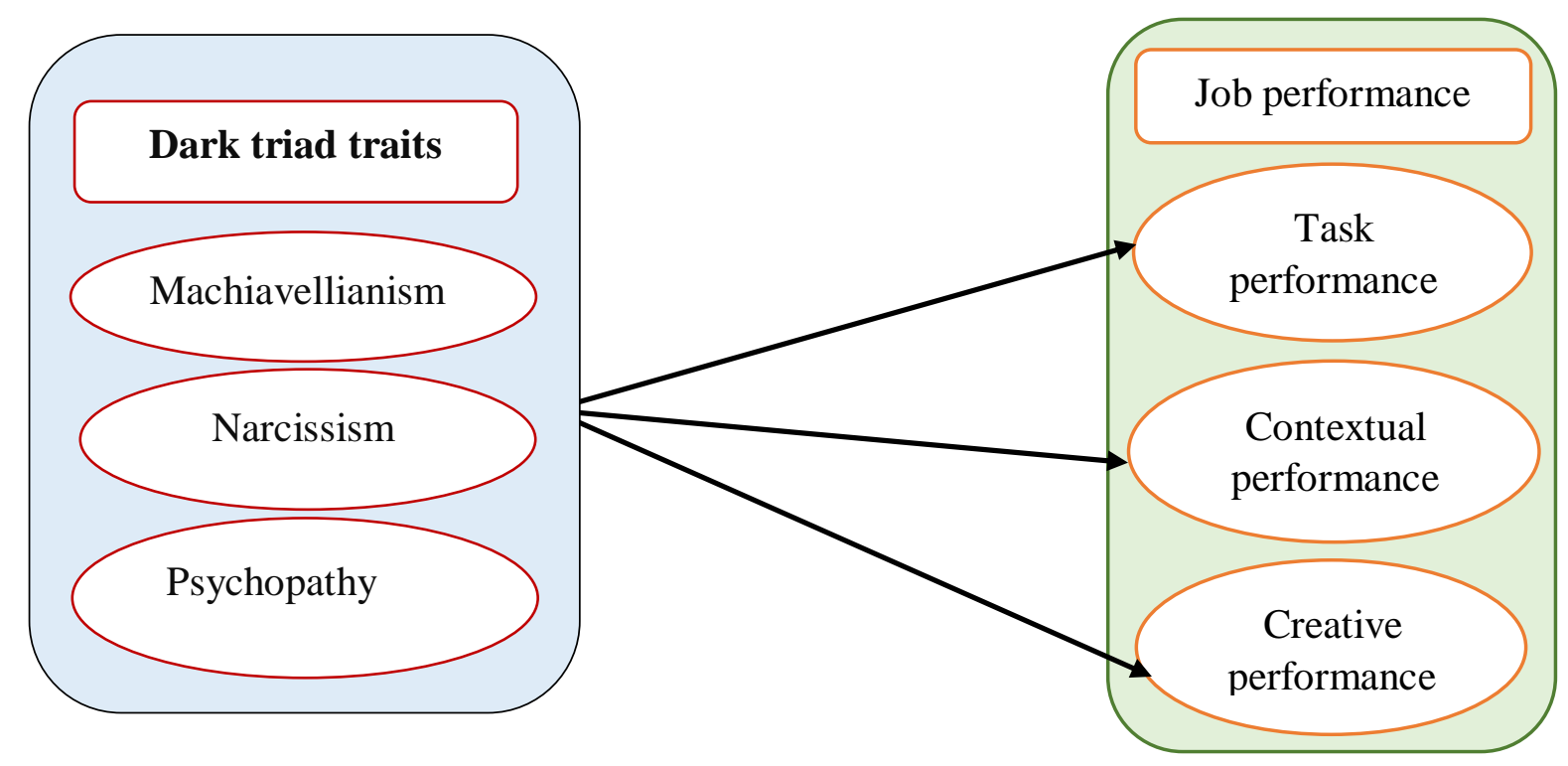

Figure 1. The study hypothesized model

\section{Research method}

\subsection{Sample and Procedure}

The research's population consists of all journalists at the Egyptian National newspapers. The researchers employed a questionnaire to collect data. According to Saunders et al. (2009), the population size, the type of statistical analysis utilized in the research, the margin of error, and the confidence level are the main factors that determine the sample size. The population size was 4900 journalists at the Egyptian national newspapers according to journalism syndicate. Consequently, the sample size would be 370 journalists at a confidence level of $95 \%$ and margin of error equals $5 \%$. 
Researchers depended on a probability sampling technique specifically simple random sampling as the sample frame is known.

A questionnaire was translated into Arabic using a back-translation procedure. A pilot study is performed with 40 questionnaires. The Cronbach's alpha for perceived Machiavellianism, narcissism, and psychopathy are $0.803,0.898$, and 0.768 respectively, which indicates a good level of constructs' reliability. Further, the value of Cronbach's alpha for task performance, contextual performance, and creative performance are 0.759 , 0.871 , and 0.863 respectively, which indicates a good level of construct reliability. The researchers distributed 600 self-administered questionnaires and 410 questionnaires were collected (a response rate 68.33\%). 391 out of 410 questionnaire were valid with free of missing data. Table (1) shows the sample characteristics.

Table (1)

Description of the sample of Journalists $(N=391)$

\begin{tabular}{|c|c|c|c|}
\hline Characteristics & Frequency & Percentage & Cumulative \% \\
\hline \multicolumn{4}{|l|}{ Journalists' gender } \\
\hline Male & 279 & $\% 71.4$ & $\% 71.4$ \\
\hline Female & 112 & $\% 28.6$ & $\% 100.0$ \\
\hline Total & 391 & $\% 100.0$ & \\
\hline \multicolumn{4}{|l|}{ Journalists' age } \\
\hline $\begin{array}{c}\text { From } 20 \text { year to less than } \\
30 \text { year }\end{array}$ & 65 & $\% 16.6$ & $\% 16.6$ \\
\hline $\begin{array}{c}\text { From } 30 \text { year to less than } \\
40 \text { year }\end{array}$ & 177 & $\% 45.3$ & $\% 61.9$ \\
\hline $\begin{array}{c}\text { From } 40 \text { year to less than } \\
50 \text { year }\end{array}$ & 91 & $\% 23.3$ & $\% 85.2$ \\
\hline 50 year or more & 58 & $\% 14.8$ & $\% 100.0$ \\
\hline Total & 391 & $\% 100.0$ & \\
\hline
\end{tabular}




\begin{tabular}{|c|c|c|c|}
\hline Characteristics & Frequency & Percentage & Cumulative \% \\
\hline \multicolumn{4}{|l|}{ Job tenure } \\
\hline Less than 5 years & $\overline{41}$ & $\% 10.5$ & $\% 10.5$ \\
\hline $\begin{array}{c}\text { From } 5 \text { years to less than } \\
10 \text { years }\end{array}$ & 107 & $\% 27.4$ & $\% 37.9$ \\
\hline $\begin{array}{c}\text { From } 10 \text { years to less than } \\
15 \text { years }\end{array}$ & 131 & $\% 33.5$ & $\% 71.4$ \\
\hline 15 year or more & 112 & $\% 28.6$ & $\% 100.0$ \\
\hline Total & 391 & $\% 100.0$ & \\
\hline \multicolumn{4}{|l|}{ Relationship tenure } \\
\hline$\overline{\text { Less than } 3 \text { years }}$ & 228 & $\% 58.3$ & $\overline{\%} \% 58.3$ \\
\hline $\begin{array}{c}\text { From } 3 \text { years to less than } 6 \\
\text { years }\end{array}$ & 95 & $\% 24.3$ & $\% 82.6$ \\
\hline $\begin{array}{c}\text { From } 6 \text { years to less than } 9 \\
\text { years }\end{array}$ & 31 & $\% 7.9$ & $\% 90.5$ \\
\hline 9 years or more & 37 & $\% 9.5$ & $\% 100.0$ \\
\hline Total & 391 & $\% 100.0$ & \\
\hline
\end{tabular}

\subsection{Measures}

The researchers depended on five-point Likert scale with choices ranging from " $1=$ never" to " $5=$ always" to measure study's constructs.

\subsubsection{Dark triad traits}

Dark triad traits have three dimensions named Machiavellianism, narcissism and psychopathy. 26 items are developed to measure these constructs (Jones \& Paulhus, 2014). Machiavellianism and narcissism were measured by 9 items for each, whereas 8 items are used to measure psychopathy.

\subsubsection{Job performance}

Job performance consists of three dimensions named task performance, contextual performance, and creative performance. Task 
performance was measured by (5) items (Williams \& Andreson, 1991). 13 items were used to measure contextual performance (Borman \& Motowidlo, 1994). Lastly, creative performance was measured by (9) items developed by George and Zhou (2002).

\section{Data analysis and results}

The researchers utilized the partial least squares (PLS) analysis, more specifically Warp PLS version 6.0. PLS handles both reflective and formative constructs. Moreover, PLS analysis consists of two major models: measurement model and structural model. The measurement model examines the association between the observed variables and their latent variables. On the other hand, the structural model tests the relationships between the latent variables (Hair et al., 2014).

\subsection{Measurement model}

Measurement model analyzes individual item reliability, construct reliability, discriminant validity, and convergent validity to maintain appropriate level of internal consistency of the research's constructs. The researchers depended on a reflective measurement model statistics as it domains in management sciences (Hair et al., 2014). Table (2) clarifies that the items' factor loadings are higher than 0.50 ( $\mathrm{p}<0.001)$. Moreover, coefficients of Cronbach's alpha and coefficients of composite reliability were greater than 0.70 , which proves that the research's constructs achieve high level of internal consistency. The AVE is higher than 0.50 for each latent variable. Consequently, these constructs achieve consistent level of convergent validity.

With regard to discriminant validity, table (3) shows that the square root of average variance extracted for each construct is greater than the variance shared with the remaining constructs (Hair et al., 2014). 
Table (2) Loading, Cronbach's Alpha, Composite reliability and Average Variance Extracted

\begin{tabular}{|c|c|c|c|c|}
\hline & Loading & $\begin{array}{c}\text { Cronbach's } \\
\text { alpha }\end{array}$ & CR & AVE \\
\hline \multicolumn{2}{|c|}{ Machiavellianism } & 0.779 & 0.851 & 0.535 \\
\hline mac5 & $(0.804)$ & & & \\
\hline mac6 & $(0.617)$ & & & \\
\hline mac7 & $(0.666)$ & & & \\
\hline $\operatorname{mac8}$ & $(0.775)$ & & & \\
\hline mac9 & $(0.778)$ & & & \\
\hline \multicolumn{2}{|c|}{ Narcissism } & 0.889 & 0.911 & 0.535 \\
\hline nar1 & $(0.611)$ & & & \\
\hline nar2 & $(0.811)$ & & & \\
\hline nar3 & $(0.756)$ & & & \\
\hline nar4 & $(0.773)$ & & & \\
\hline nar5 & $(0.646)$ & & & \\
\hline nar6 & $\begin{array}{l}(0.619) \\
\end{array}$ & & & \\
\hline nar7 & $(0.782)$ & & & \\
\hline nar8 & $(0.772)$ & & & \\
\hline nar9 & $(0.781)$ & & & \\
\hline \multicolumn{2}{|c|}{ Psychopathy } & 0.851 & 0.856 & 0.544 \\
\hline psy1 & $(0.708)$ & & & \\
\hline psy4 & $(0.650)$ & & & \\
\hline psy5 & $\begin{array}{l}(0.793) \\
\end{array}$ & & & \\
\hline psy7 & $(0.746)$ & & & \\
\hline psy8 & $(0.783)$ & & & \\
\hline \multicolumn{2}{|c|}{ Task performance } & $\overline{0.733}$ & $\overline{0.834}$ & 0.557 \\
\hline $\operatorname{tas} 1$ & $(0.670)$ & & & \\
\hline $\operatorname{tas} 2$ & $(0.786)$ & & & \\
\hline
\end{tabular}




\begin{tabular}{|c|c|c|c|c|}
\hline & Loading & $\begin{array}{c}\text { Cronbach's } \\
\text { alpha }\end{array}$ & $\overline{C \text { CR }}$ & AVE \\
\hline tas3 & $(0.796)$ & & & \\
\hline $\operatorname{tas} 4$ & $(0.727)$ & & & \\
\hline \multicolumn{2}{|c|}{ "Contextual performance } & 0.821 & 0.870 & 0.529 \\
\hline cont8 & $(0.690)$ & & & \\
\hline cont9 & $(0.675)$ & & & \\
\hline cont10 & $(0.753)$ & & & \\
\hline cont11 & $(0.793)$ & & & \\
\hline$\overline{\text { cont12 }}$ & $(0.747)$ & & & \\
\hline cont13 & $(0.696)$ & & & \\
\hline \multicolumn{2}{|c|}{ Creative performance } & 0.875 & 0.903 & 0.573 \\
\hline cre1 & $(0.708)$ & & & \\
\hline cre2 & $(0.817)$ & & & \\
\hline cre3 & $(0.671)$ & & & \\
\hline cre4 & $(0.780)$ & & & \\
\hline cre7 & $(0.749)$ & & & \\
\hline cre8 & $(0.791)$ & & & \\
\hline cre9 & $(0.773)$ & & & \\
\hline
\end{tabular}

Table (3) Correlations and square Root of Average variance

Extracted

\begin{tabular}{|l||l|l|l|l|l|l|}
\hline & Machi & Narcis & Psycho & Task & Contex & Craetiv \\
\hline \hline Machi & $\mathbf{0 . 7 3 2}$ & & & & & \\
\hline Narcis & 0.676 & $\mathbf{0 . 7 3 2}$ & & & & \\
\hline Psycho & 0.644 & 0.673 & $\mathbf{0 . 7 3 8}$ & & & \\
\hline Task & -0.041 & 0.063 & -0.100 & $\mathbf{0 . 7 4 6}$ & & \\
\hline Contex & -0.005 & 0.030 & -0.091 & 0.369 & $\mathbf{0 . 7 2 7}$ & \\
\hline Craetiv & 0.076 & 0.137 & 0.012 & 0.356 & 0.629 & $\mathbf{0 . 7 5 7}$ \\
\hline
\end{tabular}

Note: square roots of average variance extracted (AVE's) shown on diagonal

$P$ value $<0.001$ 


\subsection{Hypothesis testing}

Table (4) clarifies the results of the study's hypotheses testing. Effect size used to determine the extent to which the independent variable affects the dependent variables.

Firstly, the research results showed that there is no significant effect of Machiavellianism on task performance $(\beta=-0.039, \mathrm{p}=0.221)$. While, narcissism significantly and positively affect the task performance $(\beta=0.175$, $\mathrm{p}=<0.001)$. Furthermore, Psychopathy significantly and negatively affect task performance $\quad(\beta=-0.199, p=<0.001)$. Consequently, the effect sizes were small for the effect of Machiavellianism, narcissism, psychopathy on task performance ( $f^{2}=0.04, f^{2}=0.033, f^{2}=0.022$; respectively). Consequently, H1a was partially accepted.

Secondly, both Machiavellianism and narcissism have a significant positive effect on the contextual performance $(\beta=0.094, p=0.031),(\beta=$ $0.132, p=0.004$ ) respectively. While, Psychopathy has a significant negative effect on contextual performance $(\beta=-0.104, p=0.019)$. Further, the effect sizes of Machiavellianism, narcissism and psychopathy on contextual performance were small $\left(f^{2}=0.033, f^{2}=0.039, f^{2}=0.021\right.$; respectively).Thus, the $\mathrm{H} 1 \mathrm{~b}$ was fully accepted.

Finally, there is a significant positive effect of both Machiavellianism and narcissism on creative performance $(\beta=0.084, p=0.047),(\beta=0.133, p=$ 0.012 ) respectively. However, psychopathy has no significant effect on creative performance $(\beta=-0.053, p=0.147)$. Besides that, the effect sizes of these relationships were $\left(f^{2}=0.022, f^{2}=0.028, f^{2}=0.005\right.$; respectively). As a result, the H1c was partially accepted.

The coefficients of determination $\left(\mathrm{R}^{2}\right)$ for the three dependent variables named task performance, contextual performance, and creative performance are $(0.05,0.021$ and 0.024 ; respectively). For example, about $5 \%$ of variance in task performance was explained by Machiavellianism, narcissism, and psychopathy. 
Table 4. The results of testing direct relationships

\begin{tabular}{|c||c|c||c|c|c||c||}
\hline H & $\begin{array}{c}\text { Independent } \\
\text { Variable }\end{array}$ & $\begin{array}{c}\text { Dependent } \\
\text { variable }\end{array}$ & $\begin{array}{c}\text { Path } \\
\text { coefficients }\end{array}$ & P value & $\begin{array}{c}\text { Effect } \\
\text { size }\end{array}$ & Results \\
\hline \hline H1a & Machi & Task & -0.039 & 0.221 & 0.004 & Rejected \\
\hline H1b & Machi & Contex & 0.094 & 0.031 & 0.033 & Accepted \\
\hline H1c & Machi & Creativ & 0.084 & 0.047 & 0.022 & Accepted \\
\hline H1a & Narcis & Task & 0.175 & $<0.001$ & 0.028 & Accepted \\
\hline H1b & Narcis & Contex & 0.132 & 0.004 & 0.039 & Accepted \\
\hline H1c & Narcis & Creativ & 0.133 & 0.012 & 0.028 & Accepted \\
\hline H1g & Psycho & Task & -0.199 & $<0.001$ & 0.029 & Accepted \\
\hline H1h & Psycho & Contex & -0.104 & 0.019 & 0.021 & Accepted \\
\hline H1i & Psycho & Creativ & -0.053 & 0.147 & 0.005 & Rejected \\
\hline
\end{tabular}

\section{Discussion}

The study's statistical results indicated that there are significant direct effects of perceived dark triad traits on journalists' job performance. These results are consistent with the study of Onley et al (2013) that proposed that dark triad traits could be related to positive behaviors.

Firstly, the study's results concluded that the perceived Machiavellianism traits have a significant direct positive effect on both contextual performance and creative performance but this effect is weak. This result is not consistent with the results of O'Boyle et al. (2012), Zettler \& Solga (2013), Szabo et al. (2018), and Wisse et al. (2015). While, Machiavellians are usually characterized by negative traits, they are known as being charming, charismatic, double-faced, seductive individuals, and show their sympathetic feeling to achieve their personal gains (Macneil, 2008; Spain et al., 2013; Butler, 2015). High Machiavellians often success in concealing their nature and intensions from others. All these characteristics make Machiavellian's subordinates appreciate them, support them, and comply with their instructions especially in beginning of their tenure, which in turn result in higher contextual performance. 
In journalism field, the sales volume and the spread of the journal between publics are considered the basic determinants of any chief editor's success. The chief editors usually promote the creative performance of their journalists to get access to the sources of exclusive news, write reports related to current events, and present articles suitable to public's needs. Consequently, Machiavellian leaders' behaviors sometimes reinforce their subordinate creative performance to success in their positions.

Secondly, the study's results also showed that the perceived narcissism traits significantly and positively affect task performance, contextual performance, and creative performance. The findings of this study are different from the Judge et al. (2006) who concluded that the narcissism was not related to task performance. While, Smith et al. (2016) constituted that narcissism had a significant negative effect on task performance, which is not assisted with the results of this study.

This significant positive effect may be due to the narcissistic leaders' desire to be at the heart of any success (Macneil, 2008). Further, narcissists seek to achieve their desired status, success, respect, and admiration. Thus, narcissistic leaders usually foster their subordinates to complete assigned tasks successfully, and follow their progress to meet the formal requirements of their jobs.

On the other hand, the perceived narcissism significantly and positively affect journalists' contextual performance. This result is unlike Judge et al. (2006) and Szabo et al. (2018). This finding could be rationalized as the narcissists usually try to achieve great success in their social and work life (Butler, 2015). They depend on social environment to maintain their selfperception and get positive feedback (Macneil, 2008). These narcissistic leaders' characteristics would reinforce the positive feeling of their subordinates toward the work.

Besides, the study results showed that the perceived narcissism has a significant positive effect on creative performance. This result is similar to the results of Goncalo et al. (2010) results. Further, the findings Wisse et al. (2015) are in line with the finding of this study. According to Wisse et al. (2015), the existence of high competition between narcissistic employees 
fosters their creative and innovative behaviors to get supervisor's admiration and achieve success. Knights (2014) also stated that narcissistic leaders are able to predict the future, and utilize their creative visions to have and maintain their competitive positions.

Thirdly, the study results revealed that perceived psychopathy has significant negative influence on both task and contextual performance. The results of this study are consistent with O'Boyle et al. (2012)'s results, On the contrary, Smith et al. (2016) showed that there was no significant relationship between psychopathy and task performance, which is not in the line with study's results.

The significant negative effect of psychopathy on task performance may be due to the nature of psychopathic individuals who act as a threat to the organization's performance and survival because of focusing on achieving their own interest regardless the firm's interest (Baker, 2013). Carre (2016) clarified that psychopaths may harm others to achieve their personal gain. So that, psychopaths' subordinates usually fail to complete their assigned tasks, as they force them to fulfil the tasks that achieve psychopaths' personal profit.

Furthermore, the study's results showed that perceived psychopathy significantly negatively affect the journalists' contextual performance. Smith et al. (2016) confirmed this result. Additionally, Szabo et al. (2018) explained the negative association between psychopathy and organizational citizenship behaviors. The main characteristics of psychopaths are egocentric, irrational thinking, duplicity, clod-hearted, arrogant, low conscientiousness, manipulative, grandiose, and selfish (Spain et al., 2013; Butler, 2015; Murray, 2016). Psychopaths also seek to exploit others and leave them as a victim when their utility ends (Butler, 2015). Moreover, they are also characterized by the hard treatment of their subordinates, lack rewarding other, lowrecognitions, and improper training (Murray, 2016). All these traits negatively influence the interpersonal relationship in the workplace, which in turn negatively influence contextual performance.

\subsection{Theoretical and practical implications}

The research contributes to the body of knowledge of the existing literature related to dark triad traits, and job performance. It is the first 
research that tested these variables in the developing countries context. The research contributes to fill gap in the literature review related to the research's constructs. Firstly, the research participates in explaining how subordinates perceive their leader's dark triad traits and examining the effect of this perception on job performance. The results indicated that perceived dark triad traits affect job performance's dimensions through fostering subordinates to exerted extra effort, cooperate with others, adopt creative ideas and solution, and persist to achieve their goals.

Moreover, this research provides significant practical implications for the chief editors of the Egyptian national journals. Firstly, the research suggested that the chief editors of Egyptian national journals should support their firms' performance and build their competitive advantage through focusing on the mutual interests between them and their employees. Further, the chief editors should not manipulate or exploit their subordinates and take into consideration their personal goals. They also should try to create workplace environment that reinforce cooperation with other, following the organization rules and instruction fairly, and sharing career experiences with coworkers. Finally, the chief editors should support creativity and the utilization of imagination, and new ideas in the workplace.

\subsection{Limitations and future research}

While the current study introduced useful theoretical and practical implications, there are still several limitations. On one level, due to time and cost constraints, the current research depended on a sample of journalists at the headquarter offices of Egyptian national newspapers in Cairo governorate. Therefore, the study suggested that future researches could depend on a larger sample size from other national newspapers' offices in different Egyptian governorates.

On the other level, this study analyzed research hypotheses via questionnaire that provides cross-sectional data. Thus, further studies may benefit from longitudinal study to observe the changes in job performance as a result of different levels of leader's dark triad traits. Finally, the study depended on a sample from the Egyptian national journalism (developing country). Therefore, further researches that focus on developed countries and compare the results with the study's results will make great contributions. 


\section{References}

Abod, E. T. (2001). Interpersonal characteristics and citizenship climate as predictors of contextual performance in organizations. Dissertation Abstracts International: Section B: The Sciences and Engineering, 62(1-B), 582.

Amabile, T. M. (1983). The social psychology of creativity: A componential conceptualization. Journal of Personality and Social Psychology, 45(2), 357-376.

Arendt, L. A. (2006). Leaders' use of positive humor: effect followers' selfefficacy and creative performance. The University of WisconsinMilwaukee.

Baker, M. W. (2013). A Multiple case study of the dark side of leadership: an exploration of executives who led their companies to disastrous results versus exemplary CEOs who did not. Regent University.

Bellia, R. E (2007). Attitudinal and situational antecedents as predictors of contextual and task performance: moderating effects of commitment and perceived supervisor support on the relationship between task characteristics and performance measures. The Marshall Goldsmith School of Management, Alliant International University, Los Angeles.

Benton, D. M. (2016). Examining dark Side leadership and impression management of King David: a social-culture texture analysis of 2 Samuel 11. Regent University.

Bonness, B. M. (2007). Using structured employment interviews to predict task and contextual performance. The University of Missouri.

Borman, W.C \& Motowidlo, S. J. (1997). Task performance and contextual performance: The meaning for personnel selection research. Human Performance, 10 (2), 99-109.

Brownlee, A. L. (1999). Motivational effects of accountability and recognition on task and contextual performance, University Florida.

Bulter, J.C. (2015). Dark triad, employee creativity, and employee performance in the new venture context. Oklahoma State University.

Carre, J. R. (2016). Making decisions affecting oneself versus others: the mediating effect of interpersonal closeness and dark triad traits. The University of Texas at El Paso. 
Chatterjee, D. (2016). The effect of time pressure on creative performance: role of intellect \& Affect. Michigan State University.

Christie, R., Geis, F. L. (1970). Studies in Machiavellianism. United States of America, Academic Press, INC.

Cleckley, H. (1984). The mask of sanity: an attempt to clarify some issues about the so-called psychopathic personality. William a Dolan, fifth edition.

Deshong, H. L. (2013). Personality and workplace behaviors: assessing the five- factor model and dark triad in relation to counterproductive workplace behaviors. The Oklahoma State University.

Gilson, L.L. (2000). The role of procedural justice in the relationship between demographic diversity, dissimilarity, work-related affective outcomes, and creative performance. Georgia Institute of Technology.

Goncalo, J. A., Flynn, F. J., \& Kim, S. H. (2010). Are two narcissists better than One? The link between narcissism, perceived creativity, and creative performance. Personality and Social Psychology Bulletin, 36(11), 1484-1495.

Grijalva, E. \& Newman, D.A. (2015), Narcissism and counterproductive work behavior (CWB): meta-analysis and consideration of collectivist culture, big five personality, and narcissism's facet structure. Applied Psychology, 64 (1), 93-126.

Grondel, D.T. (2016). An investigation of the relationship between leadership styles and dark leadership behavior in law enforcement executives. Brandman University, Irvine, California.

Guerra, S. J. (2015). Contextual performance: An exploration of individual job performance and its relationship with patient contact. Capella University.

Hair, J. F., Hult, G.T.M., Ringle, C.,\& Sarstedt, M. ( 2014). A Primer on Partial Least Squares Structural Equation Modeling (PLS-SEM). Sage Publications, INC.

Hare, R. (1993). Without conscience: the disturbing world of psychopaths among us. Guilford Publications, INC.

Hare, R. D. (1996). Psychopathy: A clinical construct whose time has come. Criminal Justice and Behavior, 23(1), 25-54. 
Jeon, K. N. (2008). A comparison of the effects of divergent thinking, domain knowledge, and interest on creative performance in art and math. Purdue University, West Lafayette, Indiana.

Johnson, E. C. (2009). A multi-level investigation of overall job performance ratings. North Carolina State University, Raleigh, North Carolina.

Jones, D. N., \& Paulhus, D. L. (2014). Introducing the Short Dark Triad (SD3): A Brief Measure of Dark Personality Traits. Assessment, 21(1), $28-41$.

Judge, T. A., LePine, J. A., \& Rich, B. L. (2006). Loving yourself abundantly: Relationship of the narcissistic personality to self- and other perceptions of workplace deviance, leadership, and task and contextual performance. Journal of Applied Psychology, 91(4), 762-776.

Klann, M. (2017). The dark tetrad and its relations with maladaptive personality traits and sexual tactics. Southern Illinois University Edwardsville.

Knights, A. R. (2014). CEO grandiose and vulnerable narcissism and firm performance: A systematic review, theoretical model and empirical test. Binghamton University, New York.

Knight, N. M. (2016). The dark triad and HEXACO personality model in relational aggression. The University of Southern Mississippi.

Lucas, B. J. (2015). People underestimate the value of persistence for creative performance. Northwestern University.

MacNeil, B. M. (2008). The dark triad and faking ability on self-report personality inventories and autobiographical accounts. Queen's University, Kingston, Ontario, Canada.

Madjar, N., Oldham, G. R., \& Pratt, M. G. (2002). There's no place like home? The contributions of work and nonwork creativity support to employees' creative performance. Academy of Management Journal,45 (4), 757-767.

Montag, T., Maertz, C. P., \& Baer, M. (2012). A critical analysis of the workplace creativity criterion space. Journal of Management, 38(4), 1362-1386.

Motowidlo, S. J., \& Van Scotter, J. R. (1994). Evidence that task performance should be distinguished from contextual performance. Journal of Applied Psychology, 79(4), 475-480. 
Murray, L. (2016). The effect of dark triad on military subordinates. Alliant International University.

O'Boyle, E. H., Jr., Forsyth, D. R., Banks, G. C., \& McDaniel, M. A. (2012). A meta-analysis of the dark triad and work behavior: A social exchange perspective. Journal of Applied Psychology, 97(3), 557-579.

Paulhus, D. L., \& Williams, K. M. (2002). The dark triad of personality: Narcissism، Machiavellianism, and psychopathy. Journal of Research in Personality, 36, 556-563.

Rauthmann, J. F. (2012). The Dark Triad and Interpersonal Perception: Similarities and Differences in the Social Consequences of Narcissism, Machiavellianism, and Psychopathy. Social Psychological and Personality Science, 3(4), 487-496.

Saunders, M., Lewis., P., Thornhill, A. (2009).Research methods for business students. Pearson Education Limited, Fifth edition.

Scherer, K. T., Baysinger, M., Zolynsky, \& D., LeBreton, J. M. (2013). Predicting counterproductive work behaviors with sub-clinical psychopathy: Beyond the five factor model of personality. Personality and Individual Differences, 55 (3), 300-305.

Smith, F. S., \& Lilienfeld, S. O. (2013). Psychopathy in the workplace: The knowns and unknowns. Aggression and Violent Behavior, 18 (2), 204218.

Smith, M. B., Craig Wallace, J., \& Jordan, P. (2016). When the dark ones become darker: How promotion focus moderates the effects of the dark triad on supervisor performance ratings. Journal of Organizational Behavior, 37(2), 236-254.

Spain, S. M., Harms, P., \& LeBreton, J. M. (2014). The dark side of personality at work. Journal of organizational behavior, 35(S1), S41S60.

Szabó, Z. P., Czibor, A., Restás, P., \& Bereczkei, T. (2018). “The Darkest of all" The relationship between the Dark Triad traits and organizational citizenship behavior. Personality and Individual Differences, 134, 352356.

Merino-Tejedor, E., Hontangas-Beltrán, P. M., Boada-Grau, J., \& LucasMangas, S. (2015). Hardiness as a moderator variable between the Big- 
Five Model and work effort. Personality and Individual Differences, 85, 105-110.

Togade, D. (2017). Creativity in the Present Moment: A Behavior-Analytic Exploration of the Effects of Mindfulness Practice on Adult's Creative Performance. The Chicago School of Professional Psychology.

Williams, L. J., \& Anderson, S. E. (1991). Job satisfaction and organizational commitment as predictors of organizational citizenship and in-role behaviors. Journal of management, 17(3), 601-617.

Wisse, B., Barelds, D. P., \& Rietzschel, E. F. (2015). How innovative is your employee? The role of employee and supervisor Dark Triad personality traits in supervisor perceptions of employee innovative behavior. Personality and Individual Differences, 82, 158-162.

Zettler, I., \& Solga, M. (2013). Not enough of a 'dark'trait? Linking Machiavellianism to job performance. European Journal of Personality, 27(6), 545-554. 